\title{
Unusual endoscopic findings in an immunosuppressed patient
}

Immunosuppressed patients are susceptible to infections by opportunistic agents such as Leishmania that could cause visceral leishmaniasis with gastrointestinal involvement in up to $10 \%$ of cases.

We report a 41-year-old man with human immunodeficiency virus (HIV) infection stage C3 with CD4 lymphocytes $81 / \mathrm{mm}^{3}, 4,070$ leukocytes (47.2\% lymphocytes, $0.0 \%$ eosinophils, rest of differential normal) treated with antiretroviral therapy (dolutegravir/abacavir/lamivudine) with good adherence. He also reported mesangiocapillary glomerulonephritis type-1, hepatocutaneous porphyria, and a 7-year history of recurrent visceral leishmaniasis treated with liposomal amphotericin B as secondary prophylaxis. Esophagogastroduodenoscopy and colonoscopy indicated for chronic diarrhea and anemia performed 5 years ago displayed antral erythema, mild nodular appearance in the duodenal mucosa, and normal colonic mucosa. Gastric, duodenal, and colonic biopsies revealed Leishmania spp despite treatment with liposomal amphotericin B.

A video capsule endoscopy (VCE) was now indicated for persistent diarrhea. Enteropathy with atrophic and patchy, marked edema of the villus, and whitish nodularity with a "river bedrock" appearance ( $\triangleright$ Fig. $1-3$ ) in the duodenum and jejunum were identified ( $\triangleright$ Video 1 ). Further gastric and duodenal biopsies showed an accumulation of macrophages in the lamina propria of the mucosa with intracytoplasmatic Leishmania spp (> Fig.4). Treatment with meglumine antimoniate was initiated owing to previous failure with liposomal amphotericin $B$, without response.

Some cases of visceral leishmaniasis showing non-specific findings (atrophy, edema, and whitish nodular mucosa) on esophagogastroduodenoscopy have been reported $[1,2]$, with the mucosa appearing normal in up of $45 \%$ of cases $[3,4]$. There is only one case reporting

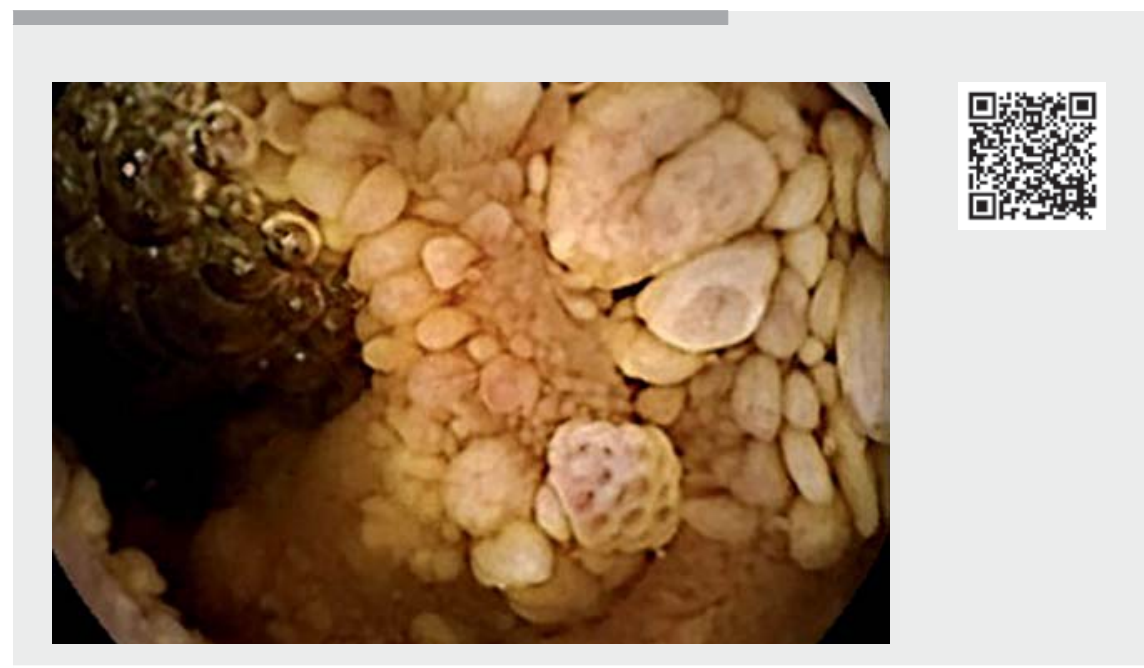

Video 1 Unusual endoscopic findings in an immunosuppressed patient.

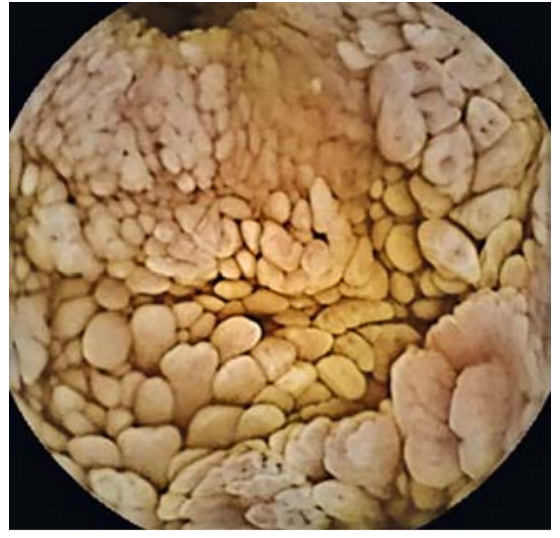

- Fig. 1 Marked edema of villi and whitish nodularity in the proximal duodenum.

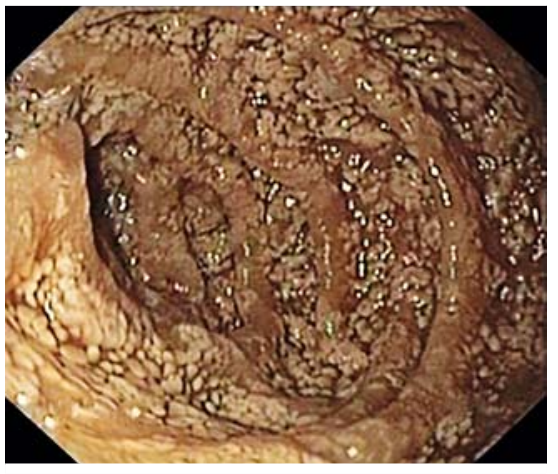

- Fig. 3 Atrophic and patchy duodenal pattern with whitish nodularity observed on esophagogastroduodenoscopy.

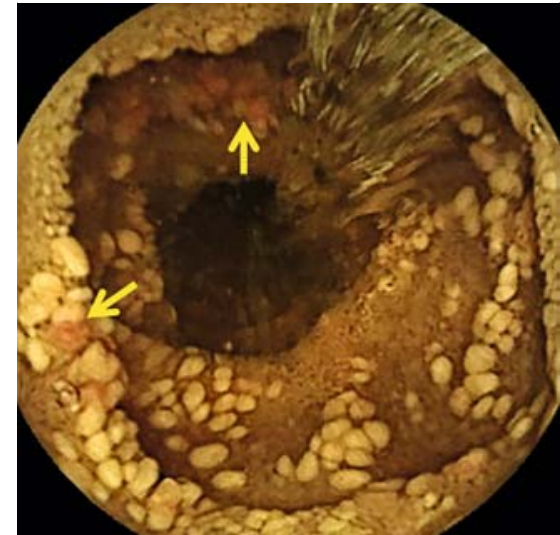

Fig. 2 Isolated erythematous nodules in the jejunum (arrows).

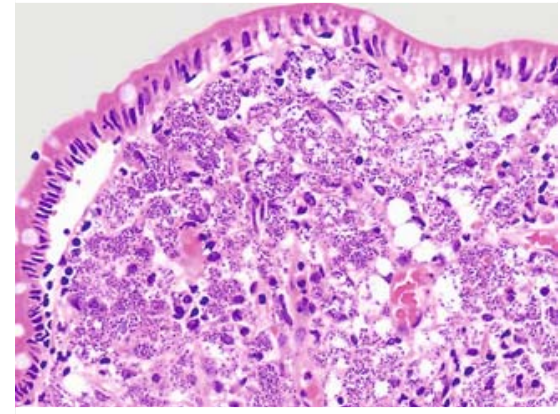

- Fig. 4 Accumulation of macrophages in the lamina propria of the mucosa with amastigotes of Leishmania protozoa in their cytoplasm; hematoxylin and eosin, $\times 40$. 
VCE findings of visceral leishmaniasis in an immunocompromised patient with a diffuse intestinal atrophic pattern [5]. We observed a similar enteropathy, although in a patchy distribution, on VCE and esophagogastroduodenoscopy. Atrophic enteropathy displayed as a "river bedrock" appearance would be a possible sign of an advanced stage of life-threatening visceral leishmaniasis. VCE may provide useful information on diagnoses, extension, and severity of gastrointestinal lesions in patients with severe immunosuppression and gastrointestinal symptoms.

Endoscopy_UCTN_Code_CCL_1AC_2AG

Competing interests

The authors declare that they have no conflict of interest.

The authors

\footnotetext{
Victoria Alejandra Jimenez-Garcia ${ }^{1,2} \odot$, Rafael Romero-Castro ${ }^{1,2}{ }^{\odot}$, Juan Rios-Martin ${ }^{3}$, Federico Argüelles-Arias ${ }^{4,5}$, Adoracion Valiente-Mendez ${ }^{6}$, Pedro Hergueta-Delgado ${ }^{1}$, Angel Caunedo-Alvarez ${ }^{1,4}$

1 Virgen Macarena University Hospital, Endoscopy Division, Sevilla, Spain

2 Hospital Vithas Nisa Sevilla, Endoscopy Unit, Sevilla, Spain

3 Virgen Macarena University Hospital, Pathology Division, Sevilla, Spain
}

4 Virgen Macarena University Hospital, Gastroenterology Division, Sevilla, Spain

5 University of Seville, Department of Medicine, Seville, Spain

6 Virgen Macarena University Hospital; Unidad Clínica de Enfermedades Infecciosas, Microbiología y Medicina Preventiva; Universidad de Sevilla and Instituto de Biomedicina de Sevilla, Seville, Spain

\section{Corresponding author}

\section{Victoria Alejandra Jimenez-Garcia, MD,} PhD

Virgen Macarena University Hospital, Endoscopy Division, Av. Dr. Fedriani s/n, 41009, Seville, Spain drajimenezg@hotmail.com

\section{References}

[1] Samiullah S, Dinneen HS, Klein KM et al. Endoscopic appearance of duodenal mucosa in GI leishmaniasis. Gastrointest Endosc 2013; 78: 962-963

[2] Egea Valenzuela J, Baños Madrid R, Rodrigo Agudo JL et al. Duodenal leishmaniasis in a HIV patient. Rev Esp Enferm Dig 2009; 101: 60-62

[3] Laguna F, García-Samaniego J, Soriano V et al. Gastrointestinal leishmaniasis in human immunodeficiency virus-infected patients: report of five cases and review. Clin Infect Dis 1994; 19: 48-53

[4] Gómez-Espín R, Fuentes E, López-Espín MI et al. Visceral leishmaniasis diagnosed by double balloon enteroscopy. Rev Esp Enferm Dig 2012; 104: 333-334

[5] Marinoni B, Tontini GE, Maggioni M et al. Intestinal leishmaniasis: a rare case of enteropathy. Endoscopy 2020; 52: E335-E336
Bibliography

Endoscopy 2021; 53: E440-E441

DOI 10.1055/a-1328-2365

ISSN 0013-726X

published online 27.1.2021

(c) 2021. Thieme. All rights reserved.

Georg Thieme Verlag KG, Rüdigerstraße 14,

70469 Stuttgart, Germany

\section{ENDOSCOPY E-VIDEOS}

https://eref.thieme.de/e-videos

Endoscopy E-Videos is a free access online section, reporting 回些: on interesting cases and new techniques in gastroenterological endoscopy. All papers include a high quality video and all contributions are freely accessible online.

This section has its own submission website at https://mc.manuscriptcentral.com/e-videos 